\title{
Comparative evaluation of ropivacaine hydrochloride $0.75 \%$ and ropivacaine hydrochloride $0.75 \%$ with clonidine in interscalene brachial plexus block for orthopaedic upper limb surgery
}

\author{
*R Deshmukh', S Rashid ${ }^{2}$, SK Gulati ${ }^{3}$ \\ Senior Resident ${ }^{l}$, Department of Anaesthesia, Critical Care and Pain, TATA Memorial Hospital, \\ Mumbai, Senior Resident ${ }^{2}$, Department of Anaesthesia, SKIMS Medical College, Srinagar, Professor and \\ former Head of Department ${ }^{3}$, Government Medical College, Amritsar and Amandeep Hospital, Amritsar, \\ India.
}

\section{*Corresponding author:drdeshrosh@gmail.com}

\begin{abstract}
Background:
Certain adjuvants have been tried with local anaesthetics to enhance analgesic efficacy and extend the analgesic period post operatively. This randomized prospective double blind trial was designed to compare the effects of addition of clonidine to ropivacaine in interscalane brachial plexus block for upper limb surgery.
\end{abstract}

\section{Patients and methods:}

60 patients of age group 20 - 65 years of either sex, admitted to undergo upper limb surgeries were included. Group A - Patients receiving $30 \mathrm{ml}$ of $0.75 \%$ ropivacaine hydrochloride plus $1 \mathrm{ml}$ normal saline. Group B - Patients receiving 30ml of $0.75 \%$ ropivacaine hydrochloride plus $150 \mathrm{mcg}$ clonidine (1ml).

\section{Results:}

The total duration of sensory block in group A was $7.61 \pm 1.62$ hours while in group B was 11.62 \pm 1.84 hours. Total duration of motor block in group A was $5.95 \pm 1.38$ hours while in group B was $9.82 \pm 1.98$ hours. Duration of post-operative analgesia in group A it was $7.24 \pm 1.36$ hours and in group $\mathrm{B}$ it was $11.83 \pm 2.33$ hours. Haemodynamically both groups were stable perioperatively. Patient satisfaction score was better in group B.

\section{Conclusion:}

In conclusion, clonidine added to ropivacaine is an attractive option for improving the quality and duration of interscalene brachial plexus block in upper limb surgeries with stable perioperative hemodynamics.

Keywords: interscalene block, ropivacaine, clonidine, upper limb surgery, regional anaesthesia.

\section{Introduction}

Regional anaesthesia has more to offer in orthopaedic surgery than in any other surgical speciality. ${ }^{1} \quad$ Regional anaesthesia enables sitespecific, long-lasting, and effective anaesthesia and analgesia. Peripheral nerve blocks (PNB) can also be used as only "surgical" anaesthetic, as a "supplement" to provide analgesia and muscle relaxation along with general anaesthesia, or as the initial step in the provision of prolonged postoperative analgesia. ${ }^{2}$ Interscalene brachial block being technically simple and ease in identification of necessary landmarks, provides excellent anaesthesia for shoulder and upper arm surgeries.

Ropivacaine, with its efficacy, lower propensity for motor block and reduced potential for CNS and cardiac toxicity, appears to be an important option for regional anaesthesia and for the management of postoperative pain. ${ }^{3}$ Adjuvants to local anaesthetics for peripheral plexus blockade have been proposed to enhance the quality and duration of anaesthesia and postoperative analgesia. Clonidine is a selective $\alpha 2$ adrenergic agonist with some $\alpha 1$ agonist property. In clinical studies, the addition of clonidine to local anaesthetic solutions 
improved peripheral nerve blocks by reducing the onset time, improving the efficacy of the block during surgery and extending postoperative analgesia. $^{4}$

The present study was designed to evaluate the effect of ropivacaine hydrochloride $0.75 \%$ and addition of clonidine $150 \mathrm{mcg}$ to ropivacaine hydrochloride $0.75 \%$ on the duration of sensory and motor blockade and post-operative analgesia in interscalene brachial plexus block for various upper extremity orthopaedic procedures.

\section{Patients and Methods}

The study protocol was approved by the institutional ethics committee and informed written consent in patients own language was taken. It was a prospective, randomised, double blind study. 60 patients of American Society of Anaesthesiologists (ASA) grade 1and 2 of age group 20 - 65 years of either sex, admitted in the orthopaedic department of Amandeep Hospital, Amritsar and scheduled to undergo upper limb surgeries under interscalene brachial plexus block were the study participants.

All patients were randomly divided into two groups of 30 each, in a double blind manner. Randomisation was performed by a computer generated program by an independent statistician and concealed from patients and investigators until completion of statistical analysis. Group A Patients received $30 \mathrm{ml}$ of $0.75 \%$ ropivacaine hydrochloride plus $1 \mathrm{ml}$ normal saline. Group B Patients received $30 \mathrm{ml}$ of $0.75 \%$ ropivacaine hydrochloride plus $150 \mathrm{mcg}$ clonidine $(1 \mathrm{ml})$.

The patients were reassured; the procedure of block explained and a written informed consent was obtained from them. Interpretation of the Visual Linear Analogue Scale was explained one day prior to the surgery. On arrival in the operation room, all patients were monitored with continuous respiratory rate, pulse rate, $\mathrm{ECG}, \mathrm{SpO}_{2}$ and non-invasive blood pressure. An intravenous line was secured in the unaffected limb with $18 \mathrm{~g}$ intracath and Ringer's lactate was started. Interscalene brachial plexus block was performed with nerve locator (stimuplex, Braun Germany) by experienced anaesthesiologist who was blinded to the drug.
Sensory sensation was tested by pin prick. Motor sensation was tested using modified Bromage scale. Post-operative analgesia was given when the patient complained of pain (VAS $>3$ ). Patient satisfaction score was recorded post operatively for 24 hours.

A power analysis was performed to determine the necessary number of patients for each group, with a two sided type 1 error of $5 \%$ and study power at $80 \%$. It was estimated that 20 patients would be needed in each group in order to detect a difference of $30 \mathrm{~min}$ in duration of analgesia between two groups. Statistical analyses were performed using the SPSS version 17.0 program for Windows. We conducted a Shaipro Wilk test to verify the distribution of the data. All data were summarized as the mean $\pm \mathrm{SD}$, while those with a skewed distribution were described as a median (IQR). Student's t-test was used for continuous, normal variables. The Mann-Whitney test was used to test independent relationships between the variables that did not demonstrate normality. A two-sided $\mathrm{P}$ value $<0.05$ was considered statistically significant.

\section{Results and observations}

Both groups were compared for demographic data and there was no significant difference in age, weight and height distribution in both groups with $\mathrm{p}$ value being $>0.05$ (Table 1 ).

On comparing duration of sensory block, motor block and post op analgesia it was seen that $p$ value was $<0.05$ being statistically significant (Table 2). Total number of analgesic doses required was also less in group B, analgesic in the form of tramadol was given whenever patient demanded with VAS score $>3$ (Figure 1). As shown in Figure 2 patient satisfaction score was recorded, in group A, 15 people gave a score of 5 out of 5,13 people gave a score of 4 while 2 people gave a score of 3 . In group B, 24 people gave a score of 5,5 people gave a score of 4 and one person gave a score of 3 . 
Table 1: Comparison of age, weight and height in both groups.

\begin{tabular}{|l|l|l|l|l|l|}
\hline \multirow{2}{*}{} & \multicolumn{2}{|l|}{ Group A $(\mathbf{n = 3 0})$} & \multicolumn{2}{l|}{ Group B (n=30) } & \multirow{2}{*}{ P Value } \\
\cline { 2 - 5 } & $\begin{array}{l}\text { Mean } \mathbf{\pm} \\
\text { SD }\end{array}$ & $\begin{array}{l}\text { Min- } \\
\text { Max }\end{array}$ & $\begin{array}{l}\text { Mean } \pm \\
\text { SD }\end{array}$ & $\begin{array}{l}\text { Min- } \\
\text { Max }\end{array}$ & \\
\hline $\begin{array}{l}\text { Age } \\
\text { (years) }\end{array}$ & $\begin{array}{l}33.63 \pm \\
12.09\end{array}$ & $20-57$ & $\begin{array}{l}31.60 \pm \\
10.95\end{array}$ & $20-66$ & 0.497 \\
\hline $\begin{array}{l}\text { Weight } \\
(\mathrm{kg})\end{array}$ & $\begin{array}{l}65.07 \pm \\
9.18\end{array}$ & $50-85$ & $\begin{array}{l}68.50 \pm \\
11.22\end{array}$ & $35-88$ & 0.200 \\
\hline $\begin{array}{l}\text { Height } \\
(\mathrm{cm})\end{array}$ & $\begin{array}{l}158.60 \pm \\
5.67\end{array}$ & $\begin{array}{l}150- \\
172\end{array}$ & $\begin{array}{l}159.57 \pm \\
6.05\end{array}$ & $\begin{array}{l}148- \\
173\end{array}$ & 0.526 \\
\hline
\end{tabular}

Table 2: Comparison of total duration of sensory and motor block in both groups, also depicting total duration of post-operative analgesia and time of rescue analgesia

\begin{tabular}{|c|c|c|c|c|c|}
\hline & \multicolumn{2}{|c|}{ Group A } & \multicolumn{2}{|c|}{ Group B } & \multirow[b]{2}{*}{ P Value } \\
\hline & $\begin{array}{l}\text { Mean } \\
\pm \text { SD }\end{array}$ & $\begin{array}{l}\text { Min- } \\
\text { Max }\end{array}$ & $\begin{array}{l}\text { Mean } \\
\pm \text { SD }\end{array}$ & $\begin{array}{l}\text { Min- } \\
\text { Max }\end{array}$ & \\
\hline $\begin{array}{l}\text { Duration of } \\
\text { Sensory Block } \\
\text { (hrs) }\end{array}$ & $\begin{array}{l}7.61 \pm \\
1.62\end{array}$ & $5-12$ & $\begin{array}{l}11.62 \pm \\
1.84\end{array}$ & $7-14$ & $<0.001$ \\
\hline $\begin{array}{l}\text { Duration of Motor } \\
\text { Block (hrs) }\end{array}$ & $\begin{array}{l}5.95 \pm \\
1.38\end{array}$ & $4-9$ & $\begin{array}{l}9.82 \pm \\
1.98\end{array}$ & $5-15$ & $<0.001$ \\
\hline $\begin{array}{l}\text { Duration of post } \\
\text { op analgesia(hrs) }\end{array}$ & $\begin{array}{l}7.24 \pm \\
1.36\end{array}$ & $\begin{array}{l}4.3- \\
9.3\end{array}$ & $\begin{array}{l}11.83 \pm \\
2.33\end{array}$ & $\begin{array}{l}5.3- \\
16.0\end{array}$ & $<0.001$ \\
\hline $\begin{array}{l}\text { Time of rescue } \\
\text { analgesia (hrs) }\end{array}$ & $\begin{array}{l}9.20 \pm \\
2.02\end{array}$ & $6-18$ & $\begin{array}{l}13.38 \pm \\
2.32\end{array}$ & $8-17$ & $<0.001$ \\
\hline
\end{tabular}

Figure 1: Graph showing total number of analgesic doses in $24 \mathrm{hrs}$

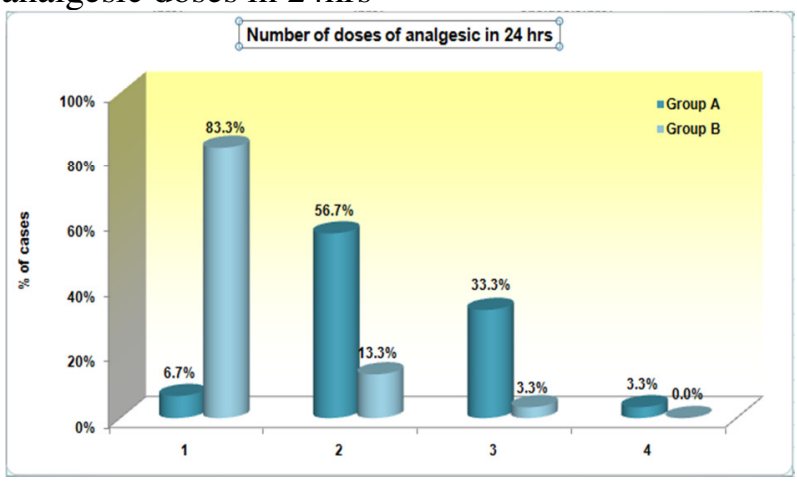

Figure 2: Patient satisfaction score

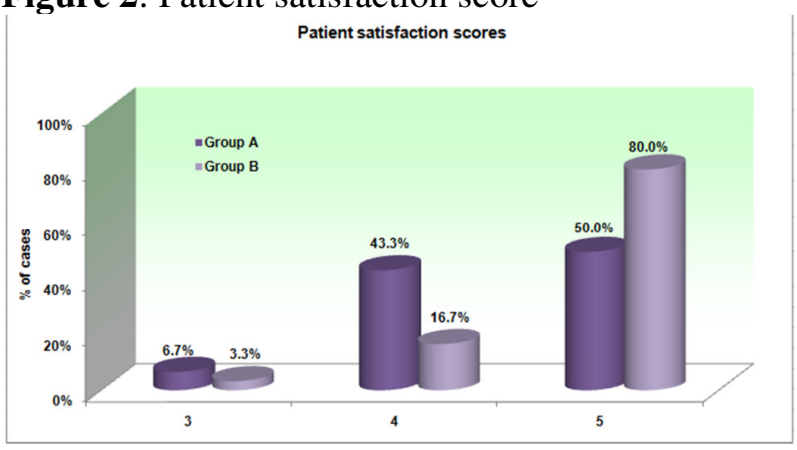

Figure 3: Graph showing VAS score in both groups. VAS score showed two peaks in group A with early peak at around 8-10hrs while in group B single peak was seen around 12-15 hrs.

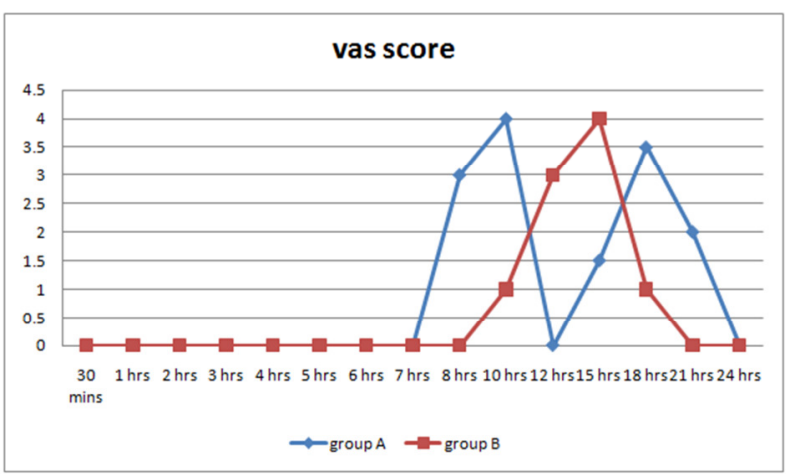

\section{Discussion}

Peripheral nerve blockade has become an essential and growing part of anaesthesia. Brachial plexus blockade provides excellent anaesthesia for upper extremity. The popularity of interscalene approach and utility stem from the excellent anaesthesia it provides for painful orthopaedic procedures and vascular procedures of shoulder and upper arm and the analgesia it supplies after discharge. ${ }^{5}$ Ropivacaine is a long acting amide local anaesthetic with a potentially improved safety profile as compared to bupivacaine. Historically, bupivacaine has been clinically used as it had longer duration of action. Subsequently, it was found that 'propyl' (ropivacaine) derivatives of pipecoloxylidides were less toxic than butyl derivatives (bupivacaine). ${ }^{6}$ Human trials have demonstrated less cardiac depression and fewer central nervous system side effects when ropivacaine is injected intravenously. ${ }^{7}$ Knudsen et al in 1997 presented data in which they compared the incidence of CNS symptoms and changes in echocardiography and electrophysiology during i.v. infusion of ropivacaine, bupivacaine and placebo. These preclinical studies showed that ropivacaine is less CNS and cardiotoxic than bupivacaine and the potential of ropivacaine to produce CNS and cardiotoxicity is also less in humans. ${ }^{8}$

A drug that has a fast onset, long duration and minimal toxicity profile could be an advantage. In order to have early onset and prolonged duration of peripheral nerve block, certain drugs have been added to local anaesthetics. Clonidine is one such drug that appears to have a distinct benefit when 
administered as an adjuvant without major side effects.

Clonidine and local anaesthetic agents have a synergistic action. Clonidine has been shown to have beneficial effect in central neuraxial blocks and other regional blocks by increasing the duration inflammatory stress response.

El Saied et al showed an increase in sensory block in the clonidine group from 489 to 628 minutes and increase in duration of motor block in the clonidine group from 552 to 721 minutes, in accordance with our study. ${ }^{10}$ Similarly in study done by Cucchiaro et al, a variety of blocks were given, which demonstrated that the addition of clonidine to bupivacaine and ropivacaine can extend sensory blocks by a few hours and increase incidence of motor blocks. ${ }^{11}$

Severe postoperative pain remains a widespread but still underestimated problem. Extensive studies have demonstrated that despite present-day improvements in pain treatment, many patients still suffer from moderate to severe postoperative pain. Severe pain is associated with decreased patient satisfaction, delayed postoperative ambulation, the development of chronic postoperative pain, an increased incidence of pulmonary and cardiac complications, and increased morbidity and mortality. ${ }^{12}$

Increase in post-operative analgesia of $415.4 \pm$ $38.18 \mathrm{~min}$ in Group A (clonidine) compared to $194.2 \pm 28.74 \mathrm{~min}$ in Group B (control) was shown in study done by Chakrobarty et al. ${ }^{4}$ In our study we found increase in duration of postoperative analgesia, along with decreased requirement of analgesic doses in group B. In terms of patient satisfaction score group B showed improvement in comparison to group A.

\section{Conclusion}

The study concludes that clonidine $150 \mathrm{mcg}$ in $30 \mathrm{ml}$ of ropivacaine $0.75 \%$ significantly enhances the quality of interscalene brachial plexus block in upper limb surgeries with prolonged duration of sensory and motor block, thus enhancing postoperative analgesia. These benefits were not associated with any significant haemodynamic changes and adverse effects. The cases with addition of clonidine had better quality of anaesthesia and analgesia in patients undergoing upper limb surgeries with a better patient satisfaction score.

\section{References}

1. Khanduri KC. Regional anesthesia techniques for orthopaedic surgery. Medical journal armed forces India 2008;64: 108 - 10 . http://dx.doi.org/10.1016/S0377-1237(08)80048-2

2. Liu S S, Lin Yi. Local anesthetics. Clinical Anaesthesia sixth edition $2009: 540-41$. PMCid:PMC2784484

3. Kutiala G, Chaudhary G. Ropivacaine : A review of its pharmacology and clinical use. Indian journal of Anaesthesia 2011; 55 (2): 104 - 9.

4. Chakraborty S, Chakrabarti J, Mandal M C, Hazra A, Das S. Effect of clonidine as an adjuvant in bupivacaine induced supraclavicular brachial plexus block: A randomized controlled trial. Indian Journal of Pharmacology 2010 April; 42 (2) : 74 77.

http://dx.doi.org/10.4103/0253-7613.64498

PMid:20711369 PMCid:PMC2907018

5. Klein ST, Evans H, Neilson KC et al. Peripheral nerve block techniques for ambulatory surgery. Anesthesia Analgesia 2005;101: 1663 - 76. http://dx.doi.org/10.1213/01.ANE.0000184187.028 $\underline{87.24}$

PMid:16301239

6. Agarwal A, Verma RK. Srivastava S. Ropivacaine - The latest local anaesthetic in the Indian market. Journal of anesthesiology and clinical pharmacology 2010;26 (2) : 223 - 28 .

7. Klein SM, Greengrass RA, Steele SM, et al. A comparison of $0.5 \%$ bupivacaine, $0.5 \%$ ropivacaine and $0.75 \%$ ropivacaine foe interscalene brachial plexus block. Anesthesia Analgesia 1998; 87: 1316 -9 .

PMid:9842819

8. Knudsen K, Suurkula MB, Blomberg S, Sjavall J, Edvardsson N. Central nervous and cardiovascular effects of IV infusions of ropivacaine, bupivacaine and placebo in volunteers. British journal of anaesthesia1997;78 : $507-14$.

http://dx.doi.org/10.1093/bja/78.5.507

PMid:9175963

9. Singh S, Aggarwal A. A randomized controlled double blinded prospective study of the efficacy of clonidine added to bupivacaine as compared with bupivacaine alone used in supraclavicular brachial plexus block for upper limb surgeries. Indian journal of Anaesthesia 2010; 54 (6) : 552 - 7.

10. El Saied AH, Steyn MP, Ansermino JM. Clonidine prolongs the effect of ropivacaine for axillary brachial plexus blockade. Can J Anesth2000;47 (10) : $962-7$. 
Deshmukh et al. Sri Lankan Journal of Anaesthesiology: 23(2):56-60(2015)

http://dx.doi.org/10.1007/BF03024866

PMid: 11032270

11. Cucchiaro G, Ganesh A. The effects of clonidine on post operative analgesia after peripheral nerve blockade in children. Anesthesia Analgesia 2007;104: $532-37$.

http://dx.doi.org/10.1213/01.ane.0000253548.9747

$\underline{9 . \mathrm{b} 8}$

PMid:17312203

12. Gerbershagen $\mathrm{HJ}$ et al. Pain intensity on the first day after surgery. Anesthesiology 2013;118 (4) : $934-44$.

http://dx.doi.org/10.1097/ALN.0b013e31828866b3

PMid:23392233 